über Freiwilligendienste veröffentlicht und diskutiert werden können. Mit Voluntaris wird darüber hinausgehend ein Forum geschaffen, um den fachlichen Diskurs zu Freiwilligendiensten und deren Weiterentwicklung zu führen. Dies eröffnet Organisationen und Akteuren aus den verschiedenen Freiwilligendiensten die Möglichkeit, sich austauschen und über unterschiedliche organisatorische und pädagogische Konzepte verständigen zu können.

Nicht zuletzt erwarte ich von einer Zeitschrift wie Voluntaris auch, dass sie politische Kontroversen im Kontext der Freiwilligendienste aufgreift, sich in aktuelle Debatten einmischt bzw. ein Forum für den Austausch unterschiedlicher Positionen und Konzepte bereitstellt. Derzeit sind dies zum Beispiel die Debatte zur Sinnhaftigkeit kurzzeitiger internationaler Freiwilligendienste, die Kontroverse um die Folgen einer staatlichen Steuerung für die zivilgesellschaftliche Ausrichtung der Freiwilligendienste oder auch die Frage, ob und wie sich das Profil der Dienste infolge einer Monetarisierung des Bereichs verändert.

Voluntaris könnte ein Ort sein, um notwendige Diskurse aufzugreifen, anzuregen und zu ermöglichen. Ich wünsche der Gründerin und den Gründern viel Erfolg für ein solches ambitioniertes Projekt.

\title{
JUGEND für Europa, Deutsche Agentur für das EU- Programm JUGEND IN AKTION
}

\author{
Karin Schulz \\ Programmreferentin für den Europäischen Freiwilligendienst bei JUGEND \\ für Europa|schulz@jfemail.de |www.jugendfuereuropa.de
}

\begin{abstract}
Noch eine Zeitschrift auf
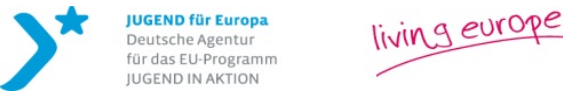
dem Stapel? Diesmal für fur das EU-Program

Freiwilligendienste. Warum sollte ich diese Zeitschrift kaufen, geschweige denn lesen? Habe ich dadurch einen Erkenntnisgewinn? - Ich würde mir von Voluntaris einen tatsächlichen Dialog zwischen Praxis, Wissenschaft und Politik wünschen, der aber nur stattfinden kann, wenn es eine gemeinsame
\end{abstract}


Sprache gibt und wenn jede Ebene von der anderen lernen möchte. Hierfür braucht es Themen, die relevant sind für alle.

Der Europäische Freiwilligendienst, der 1996 von der Europäischen Union als Pilotaktion gestartet wurde, ist seit seinem Bestehen vielfach kopiert worden. Freiwilligendienste sind in Mode, junge Menschen, denen heutzutage viele Optionen offen stehen, möchten gerne eine Auslandserfahrung machen. Die Motive sind sicher unterschiedlich. Für die einen ist es wichtig, einen Freiwilligendienst im Ausland gemacht zu haben, weil er gut in den Lebenslauf passt und nützlich für den späteren Job ist. Für die anderen ist es eine Möglichkeit, trotz fehlendem Schulabschluss Kompetenzen zu erwerben, die ihnen helfen können, ihren weiteren Lebensweg gut zu meistern. Am Ende halten alle einen „Youthpass“ in Händen, ein Zertifikat, welches ihnen die erworbenen Schlüsselkompetenzen bescheinigt.

Unbestritten ist sicher, dass es einen enormen Bedarf an freien Plätzen im Freiwilligendienst gibt. Am liebsten exotisch und am liebsten im Ausland. Der Europäische Freiwilligendienst ist hierbei jedoch der einzige Freiwilligendienst, der auf Gegenseitigkeit beruht. In demselben Maße, wie deutsche Jugendliche ins Ausland entsendet werden, werden auch Jugendliche aus anderen Ländern in deutschen Projekten aufgenommen. Das Ganze funktioniert auf gleichberechtigter Basis und mit für alle gleichermaßen gültigen Standards. Dies ist ein grundlegender Unterschied zu den ReverseProgrammen, die bei anderen Freiwilligendiensten diskutiert werden.

Die europaweit einheitliche Umsetzung des Europäischen Freiwilligendienstes kann nur gelingen dank des ständigen Dialogs im Netzwerk der über 30 Nationalagenturen und der EU-Kommission. Die beteiligten Partner Nationalagenturen wie auch Entsende- und Aufnahmeorganisationen müssen sich kontinuierlich mit den Sichtweisen in anderen Ländern auseinandersetzen und nach gemeinsamen Lösungen suchen.

Freiwilligendienste sollten im besten Falle eine win-win Situation für alle Beteiligten darstellen. Die Freiwilligen erwerben neue Kompetenzen und bringen ihr Engagement in gemeinnützigen Projekten ein. Die Projekte erfahren durch die Mithilfe von Freiwilligen und deren frische Ideen einen zusätzlichen Mehrwert. Beim Europäischen Freiwilligendienst wird zudem europäisches Bewusstsein geweckt und das Gefühl von Europäischer Bür- 
gerschaft verstärkt, was sich unter anderem an einer anteilmäßig höheren Beteiligung bei den Wahlen zum Europäischen Parlament ausdrückt als in der Vergleichsgruppe.

Warum also Voluntaris? Ich möchte mehr wissen über Langzeitwirkungen von Freiwilligendiensten. Ich möchte von der Politik wissen, warum es nach jahrzehntelangen Diskussionen immer noch keinen Freiwilligenstatus gibt. Mich würde auch die gesellschaftliche Anerkennung von Freiwilligendiensten interessieren und zwar im Vergleich mit anderen Ländern weltweit. Warum wird es Jugendlichen, die Empfänger von Sozialleistungen sind, fast unmöglich gemacht, einen Freiwilligendienst im Ausland abzuleisten? Es gibt sicher noch eine Vielzahl weiterer Themen, die im Zusammenhang mit Freiwilligendiensten von verschiedensten Seiten beleuchtet werden könnten oder gar erforscht - ich bin gespannt!

\title{
»kulturweit«
}

\author{
Anna Veigel \\ Leiterin des Freiwilligendienstes »kulturweit« bei der \\ Deutschen UNESCO-Kommissione.V.|veigel@unesco.de |www.kulturweit.de
}

Als Leiterin des Freiwilligendienstes kulturweit freue ich mich außerordentlich, dass mit Voluntaris eine Zeitschrift ins Leben gerufen wurde, die sich die Förderung des Dialogs zwischen Praxis, Wissenschaft und

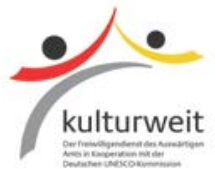
Politik im Bereich der Freiwilligendienste auf die Fahnen geschrieben hat. Die Gründung der Zeitschrift spiegelt die zunehmende Bedeutung von Freiwilligendiensten und interkulturellem und globalem Lernen in Deutschland wider und ist somit am Puls der Zeit. Ich wünsche mir eine Diskussion zu folgenden Punkten, die mir zentral erscheinen:

Praxisorientierung: Freiwilligendienste bilden einen sich momentan sehr dynamisch entwickelnden Bereich. Viele Entsendeorganisationen, aber auch die Freiwilligen und Rückkehrer selbst haben ein großes Interesse daran, ihre Tätigkeit wissenschaftlich begleiten und die Ergebnisse in ihre Tätigkeit einfließen zu lassen. Von Voluntaris erhoffe ich mir insofern für meine 